Морева Виктория Владимировна, Тамошкина Елена Викторовна, Богданова Марина Владимировна

\title{
СТРУКТУРНО-СОДЕРЖАТЕЛЬНЫЕ АСПЕКТЫ ФОРМИРОВАНИЯ ВНУТРИВУЗОВСКОЙ МОДЕЛИ ОЦЕНКИ КАЧЕСТВА ОБРАЗОВАНИЯ
}

В статье рассиатриватотя структурно-содерэсательные аспекты системы обеспечения качества образования в вузе. На основе анализа международных и национальных стандартов менеджмента качества образования в работе представлено видение модели оценки качества вуза, способной обеспечить высокое качество образования, развитие потенциала обучаюицхся и конкурентоспособности образовательной организации.

Ключевые слова: система оченки качества образования, менеджмент качества, критерии оценки качества, внутрирегиональньй анализ и оценка качества, внешняя и внутренняя оченка качества образования, политика по совериенствованию качества образовапия, дуальная система обучения.

\section{Viktoria Moreva, Elena Tamoshkina, Marina Bogdanova STRUCTURAL-CONTENT ASPECTS OF THE FORMATION}

OF UNIVERSITY'S INTERNAL MODEL OF EDUCATION QUALITY EVALUATION

The article reveals the structural and content aspects of the education quality assurance system of in higher education. Based on the analysis of international and national standards of education quality management, the article presents the vision of the university quality evluation model that can ensure the high quality of education, the development of the potential of students and the competitiveness of the educational organization.

Key words: quality assessment system of education, quality management, quality assessment criteria, intraregional analysis and quality assessment, external and internal assessment of the quality of education, policy to improve the quality of education, dual training system.

Bведение / Introduction. Рассматривая качество образования, мы говорим о нем как о сбалансированном соответствии свойств и характеристик образовательного процесса, его результатов и всей системы образования в целом существующим потребностям, установленным целям, требованиям и нормам (стандартам). Поэтому объектами оценки качества образования в вузе выступают сами результаты образования, образовательный процесс, сопутствующие ему и обеспечивающие его процессы и вся образовательная система, существующая в вузе.

При создании системы оценки качества образования в вузе необходимо учесть требования, предъявляемые к системе образования в целом. С этой целью были проанализированы Государственная программа развития образования на 2018-2020 годы и вступившая в силу с 01 января 2018 года Государственная программа на 2018-2025 годы, нацеленные на обеспечение высокого качества российского образования в соответствии с меняющимися запросами населения, а также на обеспечение конкурентоспособности российского образования на мировом рынке образования, развитие потенциала молодого поколения в интересах инновационного социально ориентированного развития страны [1, 2]. Действующая до 01 января 2018 года программа развития российского образования для достижения поставленных целей требовала решения следующих задач:

- сформировать гибкую, подотчетную обществу систему непрерывного образования, развивающую человеческий потенциал и обеспечивающую текущие и перспективные потребности социально-экономического развития Российской Федерации и повышение ее глобальной конкурентоспособности; 
- развить инфраструктуру и организационно-экономические механизмы, обеспечивающие равную доступность услуг дошкольного, общего и дополнительного образования детей, модернизировав образовательные программы в системах дошкольного и общего образования детей, направленные на получение современного качественного образования;

- обеспечить создание эффективной системы социализации и самореализации молодежи, модернизацию образовательных программ в системе дополнительного образования детей, направленных на развитие потенциала детей и молодежи;

- создать современную систему оценки качества образования на основе принципов открытости, объективности, прозрачности, общественно-профессионального участия;

- обеспечить достижение высокого стандарта качества содержания и технологий на всех уровнях образования, достижение качественно нового уровня развития эффективной системы дополнительного образования детей, повышение доступности программ социализации учащихся и студентов для успешного вовлечения их в социальную практику;

- создать необходимые условия для всестороннего развития и обеспечения эффективности и доступности системы изучения русского языка, совершенствования условий для продвижения русского языка, российской культуры в целях повышения популярности и престижа русского языка и образования на русском языке [2].

Рассматриваемая программа устанавливала индикаторы выполнения стратегии развития образования, а следовательно, и характеризующие качество образования как неотъемлемый элемент образовательного процесса. Для образовательных организаций высшего образования индикаторами выполнения программы развития образования являлось проведение следующих мероприятий:

- обеспечение условий для получения образования инвалидами и лицами с ограниченными возможностями здоровья, в том числе с использованием дистанционных образовательных технологий;

- внедрение индивидуальных учебных планов на вариативной основе;

- внедрение системы мониторинга трудоустройства и карьеры выпускников;

- проведение национальных заочных школ и ежегодных сезонных школ для мотивированных школьников;

- создание новых мест в общежитиях для студентов;

- прохождение педагогическими работниками образовательных организаций программ переподготовки или повышения квалификации по вопросам образования обучающихся с ограниченными возможностями здоровья и инвалидностью;

- $\quad$ реализация адаптированных образовательных программы, с созданием в них современных материально-технических условий в соответствии с федеральным государственным образовательным стандартом образования обучающихся с ограниченными возможностями здоровья;

- $\quad$ использование в своей деятельности единых оценочных материалов для итоговой аттестации выпускников.

Отдельные критерии развития образования устанавливались для региональных систем наличие и использование оценочных инструментов (на основе международных) для проведения внутрирегионального анализа и оценки качества образования [2].

Результаты и обсужсдение / Results and discussion. Новая программа развития российского образования также нацелена на повышение качества образования. В ней описываются конкретные целевые показатели (индикаторы) выполнения самой программы и устанавливаются следующие цели.

1-я цель - качество образования - характеризуется:

- сохранением позиции Российской Федерации в международном исследовании качества чтения и понимания текста (PIRLS), в международном исследовании качества математического и естественнонаучного образования (TIMSS); 
- п повышением позиций в международной программе по оценке образовательных достижений учащихся (PISA);

- увеличение количества российских университетов, входящих на протяжении не менее 2 лет в топ-100 мировых рейтингов университетов (их количество должно составить в 2018-2019 годах 5 и более университетов, и поэтапно увеличиться к 2025 году не менее чем до 10 университетов).

2-я цель - доступность образования - характеризуется следующими показателями:

- доступность дошкольного образования для детей от 2 месяцев до 3 лет (от 84,77 \% в 2018 году должна достигнуть к 2020 году 100 \%), для детей от 3 до 7 лет необходимо обеспечивать и сохранять на уровне $100 \%$;

- создание условий для обучения, соответствующих современным требованиям (в соответствии с ФГОС);

- доля занятого населения в возрасте от 25 до 65 лет, прошедших курсы повышения квалификации и (или) профессиональной подготовки в 2018-2025 годах должна составить $37 \%$;

- $\quad$ не менее 71-75\% детей в возрасте от 5 до 18 лет (соответственно в 2018-2025 годах) должно быть охвачено программами дополнительного образования;

3-я цель - онлайн-образование - характеризуется увеличением численности обучающихся на онлайн-курсах от 1525,5 тыс. чел. (из них 920 тыс. чел. обучающихся в организациях СПО и ВО) в 2018 году до 11000 тыс. чел. в 2025 году (из них 5000 тыс. чел. обучающихся в организациях СПО и ВО) [1].

Осуществляя внешнюю оценку качества образования Рособрнадзор совместно с региональными органами управления образованием проводит регулярные мероприятия по контролю за соблюдением образовательными организациями и их филиалами условий образовательной деятельности. Проводится мониторинг эффективности образовательных организаций. Но внешней оценки качества образования не вполне достаточно. Создание эффективной системы оценки качества образования на региональном и федеральном уровнях требует от образовательных учреждений разработки и внедрения внутривузовской системы оценки качества (проведение самообследования образовательной организации).

Внутривузовская система оценки качества образования является составляющей системы менеджмента качества вуза и включает в себя совокупность принципов, методов и инструментов измерения и сбора информации об основных показателях и параметрах технологических процессов вуза, результатах его деятельности, критериях оценки степени совершенства этих процессов, т. е. того, что в итоге непосредственно влияет на конечный результат деятельности вуза.

При разработке внутривузовской системы оценки качества образования первоначально требуется определить основные показатели, характеризующие качество образования. В перечень таких критериев следует включить показатели, устанавливаемые Министерством науки и высшего образования РФ и являющиеся общими критериями оценки качества образовательной деятельности организаций [3]. Так как процедура самообследования вуза должна отражать его отраслевую специфику, аналитическую культуру, стиль управления, то общие критерии оценки желательно дополнить специальными, характерными для конкретной образовательной организации.

Процедура самообследования не должна носить разовый характер и проводиться через определенный промежуток времени (например, в период предшествующий аккредитации), предлагается осуществлять ее как постоянный и непрекращающийся мониторинг оценки качества образования на различных этапах процесса обучения начиная с момента поиска мотивированных школьников, продолжая в период разработки и реализации образовательной программы и завершая на этапе определения степени освоения образовательной программы. Для нормального функционирования 
в вузе этих основных процессов предусматривается также их поддержка обеспечивающими процессами: управление документацией и персоналом, управление финансовой деятельностью, управление информационно-техническими ресурсами, производственной средой и пр. В перечень процессов, характеризующих качество образования в организации, необходимо включить:

1) деятельность руководства:

- $\quad$ наличие общей стратегии, политики и четко сформулированных целей организации в области качества;

- $\quad$ составление планов, в том числе по совершенствованию системы качества;

- выделение центров ответственности и закрепление за ними полномочий;

- оценка соответствия аккредитационным, лицензионным и аттестационным требованиям;

- контроль и анализ со стороны руководящих органов;

- информационное и финансовое обеспечение;

2) основные процессы системы качества:

- довузовская подготовка и прием студентов;

- проектирование, разработка и реализация основных образовательных программ;

- маркетинг;

- воспитательная и внеучебная работа с обучающимися;

- разработка и реализация программ дополнительного образования;

- научно-исследовательская деятельность;

- инновационная деятельность;

- международная деятельность.

3) обеспечивающие процессы:

- у управление персоналом;

- управление образовательной средой;

- управление информационной средой;

- управление закупками;

- $\quad$ управление инфраструктурой;

- $\quad$ управление производственной средой;

- обеспечение безопасности жизнедеятельности;

- социальная поддержка обучающихся;

4) оценка, анализ и мероприятия по совершенствованию процессов:

- мониторинг, измерение и анализ процессов;

- $\quad$ корректировка и совершенствование процессов.

При создании внутривузовской модели оценки качества образования необходимо учитывать требования и рекомендации стандартов менеджмента качества серии ISO, модель самооценки и совершенствования деятельности вуза Европейского фонда по менеджменту качества (EFQM), модель конкурса Рособрнадзора и Рособразования «Система обеспечения качества подготовки специалистов». Схема модели оценки движения организации к совершенству выглядит следующим образом (рис. 1).

В соответствии со стандартами и директивами Европейской ассоциации гарантии качества внутривузовская модель оценки качества должна постоянно совершенствоваться, следовательно, необходимо разработать политику организации по совершенствованию качества образования, основные направления и процедуры которой должны находиться в свободном доступе для всех заинтересованных лиц. Именно поэтому к разработке и участию в реализации политики улучшения качества в образовательной организации необходимо привлечь всех участников образовательного процесса: обучающихся и работодателей. 


\section{КРИТЕРИИ}

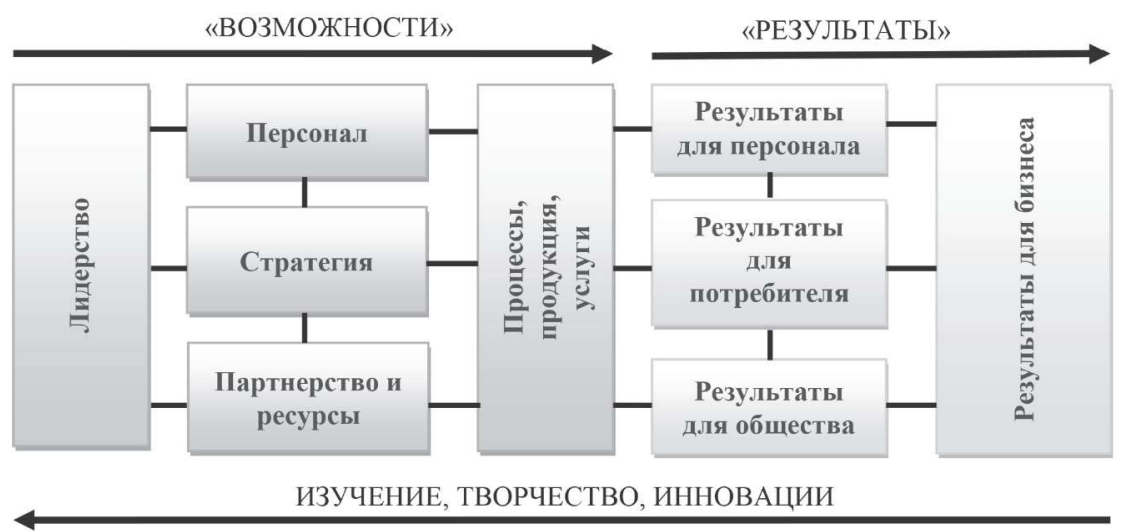

Рис. 1. Критерии оценки движения организации к совершенству

В самих образовательных организациях контроль за качеством образования и эффективностью образовательного процесса осуществляется на различных этапах обучения студентов. В вузе традиционно качество подготовки обучающегося оценивается результатами промежуточной аттестации студентов. Завершающие результаты обучения как часть составляющей качества образовательной деятельности вуза имеет немаловажное значение. Качество академической подготовки обучаюшихся зависит от компетентности и профессионализма профессорско-преподавательского состава образовательной организации, от качества учебно-методического обеспечения, развитости инфраструктуры вуза и применения в образовательном процессе передовых достижений науки.

Работодатели оценивают качество образования исходя из потребностей производства. Для работодателя важно наличие у выпускников определенных знаний, умений и практических навыков, которые должны быть приобретены ими за время обучения в вузе. Контроль за качеством образования со стороны работодателей осушествляется при привлечении работодателей к образовательной деятельности, а также их участии в составе государственных аттестационных комиссий, где они на заключительном этапе обучения осуществляют оценку качества подготовки.

Обучаюпиеся определяют качество образования наличием высокого уровня профессионального мастерства, профессиональных знаний, они также ожидают, что процесс обучения повлияет на индивидуальное развитие их личностных качеств, что позволит им занять высокое положение в обществе.

О качестве образования можно судить по статистическим данным, характеризующим профессиональную успешность выпускников, таким как их востребованность и трудоустройство, возможности и скорость профессионального роста, социальная мобильность и пр.

Так как в качественной подготовке обучающихся заинтересованы различные лица, следовательно, образовательной организации необходимо постоянно поддерживать связь со всеми потребителями образовательных услуг в целях определения степени удовлетворенности всех сторон уровнем профессионализма выпускников. Обратную связь с группами основных потребителей, как с внутренними - студентами, выпускниками, так и с внешними - предприятиями (организациями) - работодателями, государством, можно установить через анкетирование и опросы. Для этого образовательной организации следует разработать порядок и методику проведения данных процедур, способы сбора и последующей обработки получаемой информации. В круг оцениваемых показателей следует включать: основные профессиональные образовательные программы вуза; качество и содержание преподаваемого материала, работы преподавателей; участие в программах оценки и повышения качества, в том числе и международных. Последующие усилия образовательной организации должны быть направлены на проведение мероприятий по устранению выявленной неудовлетворенности и обеспечению выполнения требований, предьявляемых потребителями. 
Создавая модель внутривузовской системы оценки качества, не следует забывать существующий передовой опыт дуальной системы образования. Примерная модель внутривузовской системы оценки качества представлена на рис. 2.

Организация предлагаемой системы оценки качества должна осуществляться в плотном взаимодействии с предприятиями-партнерами, центрами занятости населения, торгово-промышленными палатами, общественными организациями. В процессе разработки и реализации данной модели обучения необходимо учитывать требования Приказа Министерства образования и науки РФ от 14 августа 2013 года № 958 «Об утверждении Порядка создания профессиональными образовательными организациями и образовательными организациями высшего образования кафедр и иных структурных подразделений, обеспечивающих практическую подготовку обучающихся, на базе иных организаций, осуществляющих деятельность по профилю соответствующей образовательной программы» [4].

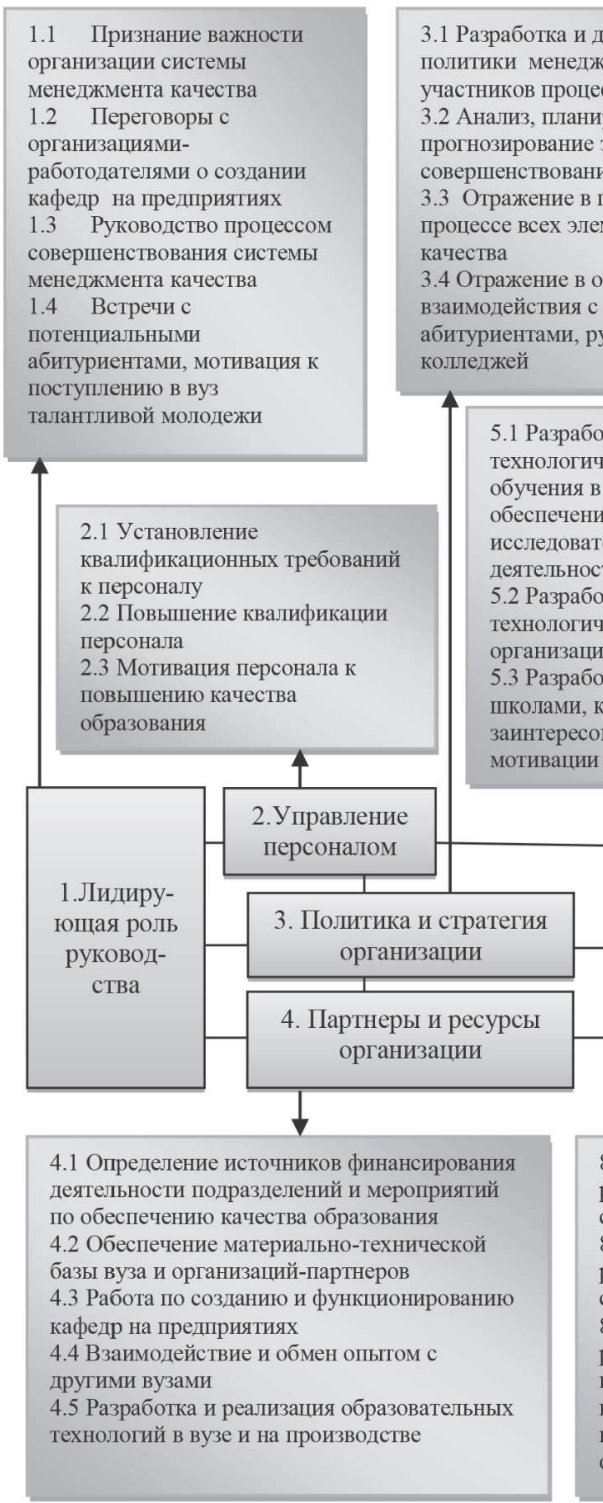

3.1 Разработка и доведение стратегии и болитики менеджмента качества вуза до всех участников процесса обучения

совершенствования качества образования

3.3 Отражение в положении об образовательном

в общей политике механизма

одателями,

водителями школ и

и реализация основных

1 Разработка и реализация основных

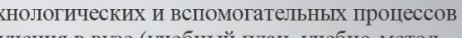
в вузе (учебный план, учебно-метод. 作, прием, обучение, научноедовательская, общественная и т.д. ттельность, трудоустройство и пр.) хнологических и вспомогательных процессов

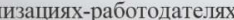

Разработка системы взаимодействия со

олами, колледжами по выявлению

интересованных в поступлении в вуз и

ции учащихся

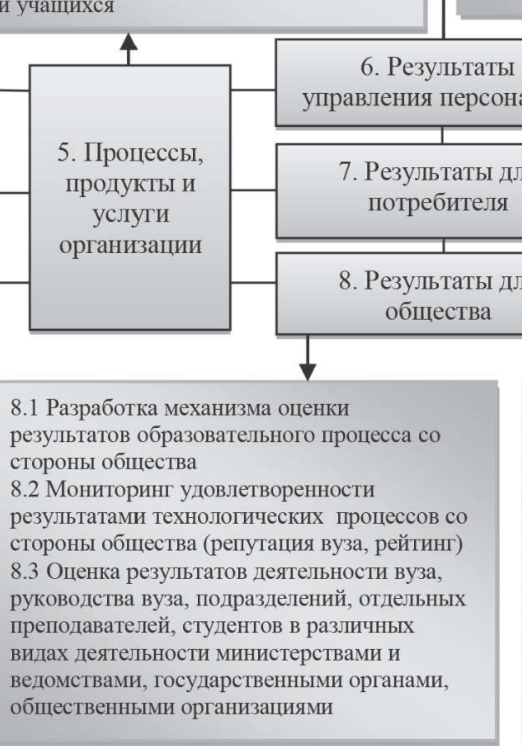

6.1 Организашия контрольной работы за качеством образовательного процесса в вузе

6.2 Мониторинг удовлетворенности результатами технологических

процессов работников вуза

6.3 Финансовые показатели деятельности вуза

6.4 Анализ выполнения показателей деятельности организации, выполнения тактических задач и стратегических целей

7.1 Разработка механизма оценки
результатов образовательного
процесса потребителями
образовательных услуг
(заказчиками, обучаюшимися,
работодателями)
7.2 Мониторинг
удовлетворенности результатами
технологических процессов
потребителями образовательных
услуг (заказчиками,

Рис. 2. Модель внутривузовской системы оценки качества образования 
Заключение / Conclusion. Рассматривая цели различных субъектов образовательного процесса можно увидеть возникающую разобщенность их интересов. Так, подготовка будущих специалистов, осуществляемая по заказу и в соответствии с потребностями рыночной экономики и работодателей, которыми в контексте современных процессов глобализации и поточного, массового производства становятся крупные корпорации, приводит к подготовке однотипных специалистов. В процессе формирования определенных профессиональных компетенций внимание сосредоточивается на развитии профессиональной пригодности обучаемого, аудиторная нагрузка по обязательным ранее (в соответствии с ГОС) дисциплинам сокращается или исключается из основных профессиональных образовательных программ полностью. Властные структуры стремятся сформировать «единое мышление» и не всегда заинтересованы в воспитании думающих, высокообразованных и независимых граждан. Включение России в Болонский процесс приводит к унификации и упрощению образовательных программ (что происходит в мировом масштабе), к подготовке специалистов по одному шаблону, снижению мотивации обучающихся к творчеству. Это впоследствии в долгосрочной перспективе может привести к снижению уровня образования человечества в целом [5].

Дуальная система образования призвана устранить подобные негативные явления, чему должна способствовать и формируемая внутривузовская модель оценки качества образования. Сложность применения элементов дуальной системы заключается в том, что отдельные образовательные организации и многие предприятия не готовы к ее реализации. Тем не менее ее применение способствует переходу на качественно новый уровень подготовки и переподготовки высококвалифицированных кадров и специалистов, в том числе и для высокотехнологичных производств, формированию общих и профессиональных компетенций выпускников образовательных учреждений, обеспечивающих их конкурентоспособность и востребованность на рынке труда, развитию эффективной системы социального партнерства в сфере профессионального образования, что, в свою очередь, отражается на качестве образования в целом.

\section{ЛИТЕРАТУРА И ИНТЕРНЕТ-РЕСУРСЫ}

1. Об утверждении государственной программы Российской Федерации «Развитие образования»: Постановление Правительства РФ от 26.12.2017 года № 1642 (ред. от 22.02.2018). URL: http:// www.consultant.ru/cons/cgi/online.cgi?req $\quad=$ doc\&base $=$ LAW $\& \mathrm{n}=292129 \& f l d=134 \& \mathrm{dst}=100018,0 \& \mathrm{r}$ $\mathrm{nd}=0.5651267882718917 \# 04747599403602748$

2. Об утверждении государственной программы Российской Федерации «Развитие образования»: Постановление Правительства РФ от 15.04.2014 года № 295. URL: http://base.garant.ru/70643472/

3. Об утверждении показателей, характеризующих общие критерии оценки качества образовательной деятельности организаций, осуществляющих образовательную деятельность: Приказ Минобрнауки России 05.12.2014 № 1547. URL: http://www.consultant.ru/document/cons_doc_LAW_174924/

4. Об утверждении Порядка создания профессиональными образовательными организациями и образовательными организациями высшего образования кафедр и иных структурных подразделений, обеспечивающих практическую подготовку обучающихся, на базе иных организаций, осуществляющих деятельность по профилю соответствующей образовательной программы: Приказ Министерства образования и науки РФ 14.08.2013 № 958. URL: http://www.consultant.ru/document/cons_doc_ LAW_151759/

5. Морева В. В. Преимущества дуальной системы обучения и ее влияние на качество образования // Современная техника и технологии: исследования, разработки и их использование в комплексной подготовке специалистов: материалы VI Международной научно-практической конференции (Невинномысск, 14.04.2017 год). Невинномысск: ГАОУ ВО «НГГТИ», 2017. С. 249-252. 


\section{REFERENCES AND INTERNET RESOURCES}

1. Obutverzhdeniigosudarstvennojprogrammy rossijskojfederaciirazviticobrazovaniyapostanovleniepravitelstva rf ot 26122017 goda 1642 (red ot 2202 2018). URL: http://www.consultant.ru/cons/cgi/online.cgi?req = doc\&base $=$ LAW\&n $=292129 \& f l d=134 \& d s t=100018,0 \&$ rnd $=0.5651267882718917 \# 04747599403602748$

2. Ob utverzhdenii gosudarstvennoj programmy Rossijskoj Federacii «Razvitie obrazovaniya»: Postanovlenie Pravitelstva RF ot 15.04.2014. goda 295. URL: http://base.garant.ru/70643472/

3. Ob utverzhdenii pokazatelej harakterizuyushchih obshchie kriterii ocenki kachestva obrazovatelnoj deyatelnosti organizacij osushchestvlyayushchih obrazovatelnuyu deyatelnost: Prikaz Minobrnauki Rossii 05. 12. 2014. № 1547. URL: http://www.consultant.ru/document/cons_doc_LAW_174924/

4. Ob utverzhdenii poryadka sozdaniya professionalny mi obrazovatelny mi organizaciyami i obrazovatelnymi organizaciyami vysshego obrazovaniya kafedr i inyh strukturnyh podrazdelenij, obespechivayushchih prakticheskuyu podgotovku obuchayushchihsya, na baze inyh organizacij osushchestvlyayushchih deyatelnost po profilyu sootvetstvuyushchej obrazovatelnoj programmy: Prikaz Ministerstva obrazovaniya i Nauki RF 14.08.2013 № 958. URL: http://www.consultant.ru/document/cons_doc_LAW_151759/

5. Moreva V. V. Preimushchestva dualnoj sistemy obucheniya i ee vliyanie na kachestvo obrazovaniya (Advantages of the dual system of education and its impact on the quality of education), Sovremennaya tekhnika $\mathrm{i}$ tekhnologii issledovaniya razrabotki $\mathrm{i}$ ih ispolzovanie $\mathrm{v}$ kompleksnoj podgotovke specialistov materialy vi mezhdunarodnoj nauchno-prakticheskoj konferencii (Nevinnomyssk 14042017 god). Nevinnomyssk: GAOU VO «NGGTI», 2017. S. 249-252

\section{СВЕДЕНИЯ ОБ АВТОРАХ}

Морева Виктория Владимировна, аспирант ГАОУ ВО «Невинномысский государственный гуманитарно-технический институт». E-mail: timpol@bk.ru

Тамоикина Елена Викторовна, кандидат педагогических наук, доцент кафедры профессионального обучения ГАОУ ВО «Невинномысский государственный гуманитарно-технический институт». E-mail: timpol@bk.ru

Богданова Марина Владимировна, кандидат педагогических наук, доцент кафедры профессионального обучения ГАОУ ВО «Невинномысский государственный гуманитарно-технический институт». E-mail: timpol@bk.ru

\section{INFORMATION ABOUT AUTHORS}

Moreva Viktoria Vladimirovna, post-graduate student «Nevinnomyssk state humanitarian technical Institute». E-mail: timpol@abk.ru

Timoshkina Elena Viktorovna, candidate of pedagogical Sciences, associate Professor of the Department of professional training «Nevinnomyssk state humanitarian technical Institute». E-mail: timpol@bk.ru

Bogdanova Marina Vladimirovna, candidate of pedagogical Sciences, associate Professor of the Department of professional training «Nevinnomyssk state humanitarian technical Institute». E-mail: timpol@bk.ru 